\title{
Study of EHD Flow Produced by Pin-Dual Ring Concentric Electrodes Generator
}

\author{
Sumariyah \\ Physics Department, Mathematics and Natural Sciences Faculty \\ Diponegoro University, Indonesia \\ Zaenul Muhlisin \\ Plasma physics, Laboratory of atoms and nuclear Group, Laboratory, Physics Department \\ Mathematics and Natural Sciences Faculty, Diponegoro University, Indonesia \\ email: muhlisin@gmail.com \\ Evi Setiawati \\ Plasma physics, Laboratory of atoms and nuclear Group, Laboratory, Physics Department \\ Mathematics and Natural Sciences Faculty, Diponegoro University, Indonesia \\ email: evi_setiawati_msi@yahoo.com
}

\begin{abstract}
The aim of this research is study of Electrohydrodynamic (EHD) flow by discharge corona generator with electrodes configuration of Pin- Dual Ring Concentric. We measured the velocity of EHD flow with electrodes configuration of Pin- Dual Ring Concentric and compare the result to Pin-Single Ring electrodes. The pin needle was made by stainless steel with a length of $50 \mathrm{~mm}$ and a tip diameter of $0.01 \mathrm{~mm}$. The dual ring electrodes constructed by two metal material connected to each other with diameter of $24 \mathrm{~mm}$ and width of $16 \mathrm{~mm}$. The thickness of rings is $2 \mathrm{~mm}$ and $3 \mathrm{~mm}$, respectively. Single ring electrode has diameter, width and thickness of 24 $\mathrm{mm}, 2 \mathrm{~mm}$ and $3 \mathrm{~mm}$, respectively. The EHD was generated by using a DC high voltage of $10 \mathrm{kV}$. The Pin act as an active electrode of corona discharge and concentric rings dual / single ring electrodes act as ions collector and passive electrodes. The velocity of EHD flow was measured by a Hot - Wire Anemometer. We found that the velocity of EHD flow with electrodes configuration of pin-dual ring concentric electrodes is larger than pin-single ring electrode. The velocity of EHD flow for two cases of electrodes configuration were saturated at the certain spacing of inter-electrodes distance. The maximum velocity of the of EHD flow using electrodes configuration of pin-dual rings concentric was $0,6 \mathrm{~m} / \mathrm{s}$ at a distance of inter-electrodes distance $6 \mathrm{~mm}$ and a voltage of $3,2 \mathrm{kV}$.
\end{abstract}

Keywords: EHD Flow, Discharge corona,pin-dual ring concentric electrodes, EHD Flow velocity.

\section{Introduction}

An Electrohydrodynamic (EHD) flow, also called wind " corona " , " electricity ", " ion", or " ion propulsion " generated by the corona discharge significantly improved heat and mass transfer ${ }^{1}$. EHD flow can be applied to drug delivery system with EHD Spraying technique $^{2}$, applied as an integrated chip cooling technique for Laptop with EHD Pump ${ }^{3,4,5}$. EHD is another application for micro fan ${ }^{6}$ and as the dryer for the biscuit industry ${ }^{7,8}$. Devices that use ionic wind flow or EHD flow by corona discharge has many advantages such as that EHD flow requires no moving parts and provides flexibility in the form of channels and free from mechanical vibration and acoustic noise.

Various attempts have been made to increase the flow rate and optimization of wind ions such as by modifying the electrode configuration, such as: pin-ring electrode configuration of ion wind generator ${ }^{9}$, parallel wire non-field ${ }^{10}$, wire-rod ${ }^{11}$ and pin-mesh with the results of that the obtained EHD flow rate is greater than pin-ring ${ }^{12}$. As for increasing the number of electrodes pin ${ }^{13,14}$ multipin-ring electrodes is made in a cylindrical tube. 
This research studies EHD flow by corona discharge with electrodes configured as a pin-dual concentric ring. The difference of this study with the study of Rickard et al. ${ }^{15}$, Rickard et al. ${ }^{16}$, Rickard et al. ${ }^{9}$ and June et al ${ }^{6}$ is that they use a pin-ring electrode pairs while the proposed research use an electrode pair pin-dual concentric ring. This electrode configuration increases velocity EHD flow compared with pin-ring electrode.

The results of this study is applied and developed in the food industry and medicine industry as an advanced dryer. Excess advanced dryers system based on EHD flow compared with conventional dryers is an advanced dryers system in addition to drying also kills bacteria sample and it can also in the field of education as a new laboratory unit in Plasma Physics field.

\section{Description of the experiments}

The first step of this research is to design a generator EHD flow. It is in the form a system of corona discharge using electrode a pin-dual concentric ring and pin-ring electrode as control of measurement results. Pin electrodes used had a diameter of $0.01 \mathrm{~mm}$ and a length of $50 \mathrm{~mm}$.

Dual concentric ring electrodes have a thickness, width and spacing between the rings the same row each $3 \mathrm{~mm} ; 2 \mathrm{~mm}$ and $2 \mathrm{~mm}$. While the diameter of the electrode dual concentric rings of magnitude, from the smallest ring for the biggest ring, each $24 \mathrm{~m}$ and $16 \mathrm{~mm}$. Ring electrode is used as control of the measurement results have diameter, width and thickness each $24 \mathrm{~mm}$, $2 \mathrm{~mm}$ and $3 \mathrm{~mm}$.

Experiment set-up in this study include the EHD flow generator with a pin-dual concentric ring electrode and pin-ring electrode, high voltage power, set voltage and current measurement tools and a set of measuring tools EHD flow velocity. The air can come from the top and out of the bottom, as shown in fig. 1

The EHD flow generated by installing a high voltage DC $10 \mathrm{KV}$ on the electrodes of the corona discharge system with a positive polarity of the pin electrodes and a negative polarity of the ring/ the dual concentric rinTo measure the high voltage used a highvoltage probe 1000: 1 , which is connected to the CRO and to measured the ion current used multimeter. As for used to measure velocity of EHD flow is devices Hot-Wire Anemometer is placed perpendicular under the pin electrode with distance is $15 \mathrm{~mm}$.
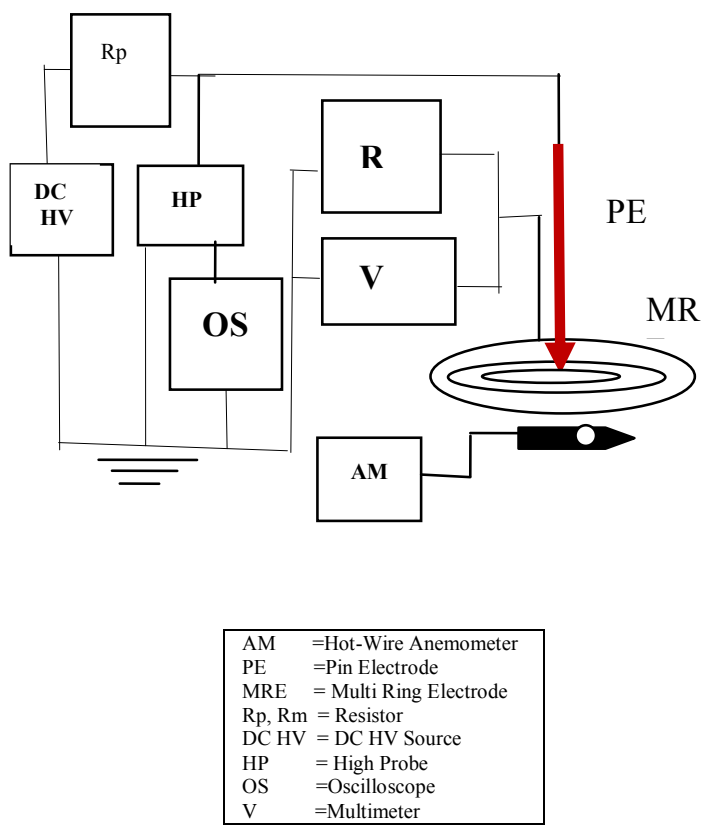

Fig. 1. Experiment set-up

\section{Results}

\subsection{The I-V characteristics.}

Graphs of ion current (I) as a function of voltage is attached $(V)$ of the measured data with the distance between the electrodes remains a characteristic of EHD flow generator hereinafter referred to as the $I-V$ characteristics. $I-V$ characteristics with fixed geometry factors shown in Fig. 2.

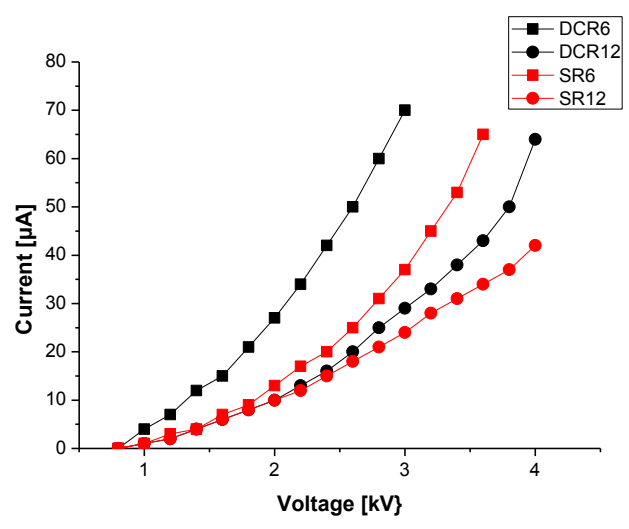

Fig.2. The $I$-V characteristics

Fig. 2 compares $I-V$ characteristics of the EHD flow generator using configuration electrode pin-dual concentric rings with pin-rings on the distance between 
the electrodes fixed. The spacing of electrodes successive: $6 \mathrm{~mm}$ and $12 \mathrm{~mm}$. In graph the $I-V$ characteristics using pin-dual consentric rings electrodes marked DCR6 and DCR12. While the $I-V$ characteristics using the electroda pin-rings marked SR6 and SR12.The $I-V$ characteristics on the spacing between the electrodes fixed, the greater the applied voltage then increased ion current . This happens, either for electrode configuration pin-dual concentric rings or the single ring. This is because the relationship between voltage and current is a parabolic function. The saturation current value proportional to the square of the value of $V$ (Is $\infty \mathrm{V}^{2}$ )

Fig.2. shown the spacing between the electrodes (d) fixed, successive $\mathrm{d}=6 \mathrm{~mm}$ dan $12 \mathrm{~mm}$ at the same value of voltage eg $\mathrm{V}=4 \mathrm{kV}$, the ion current of the EHD flow generator uses electrode configuration pin- dual concentric rings higher then the pin-ring electrode. This is because the EHD flow generator that uses electroda configuration pin-dual concentric ring having flux of electric field greater than using pin-ring electrode.

Fig. 2 shown that the onset voltage at the all distance fixed is $0.5 \mathrm{kV}$. At all the spacing between the electrodes, with increasing voltage applied to the generator then the greater the ion current that are detected and accompanied by corona discharge, then at the end break down voltage. Value of ion current during breakdown voltage, using electroda configuration pin-dual concentric ring is lower than using a pin-ring electrode. The difference in the magnitude of the ion current is due to at the breakdown voltage, the corona discharge with electrode configuration pin-dual concentric rings required more energy than the pin-ring electrode.

\subsection{EHD flow characteristics}

The EHD flow characteristics in the form of the graph of EHD flow velocity with the applied voltage. The graph of EHD flow characteristics for configuration electrode pin-dual concentric rings and pin-rings on the spacing between electrodes $6 \mathrm{~mm}$ as shown in Fig.3.

Fig.3. shown increased the voltage will lead to increased velocity of EHD flow for both EHD flow generator that uses electrodes configured a pin-dual consentric ring and pin-rings electrode. This is due to the greater voltage electrodes hit the ionization energies for the greater. This resulted in a growing number of air ions or in other words the greater the velocity EHD flow. The EHD flow velocity reached a maximum of $0.62 \mathrm{~m} / \mathrm{s}$ at a voltage of $3,2 \mathrm{kV}$.

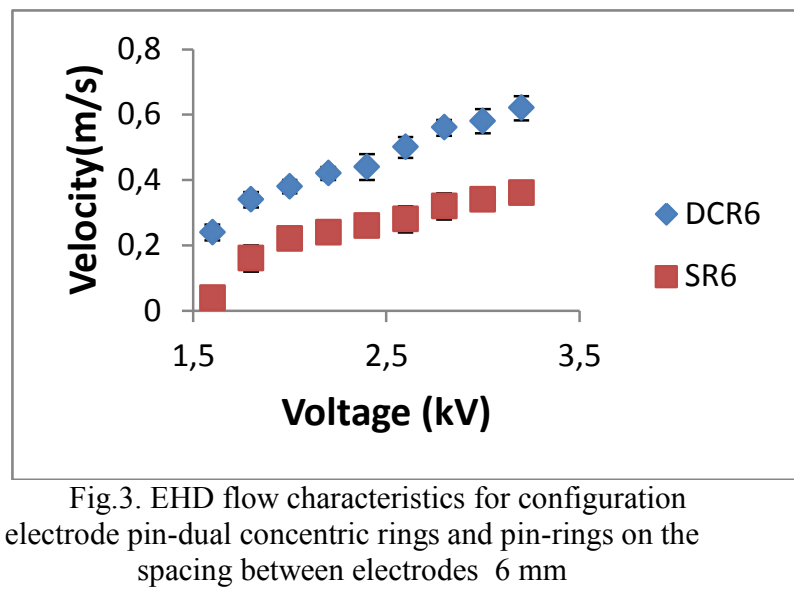

Fig.3. Shown EHD flow velocity of the generation of corona discharge using configuration electrode pindual concentric rings at the same spacing between the electrodes $6 \mathrm{~mm}$ is greater than using pin-ring electrode. This is due to using the electrode pin-dual concentric rings will happen electric flux density greater than the Pin-Rings electrode. With great power flux density will lead to increased meeting space charge ions. Ion movement towards dual ring electrode will collide with neutral air molecules with very high collision frequency. Large momentum transfer from the gas molecules to the positive ions in the region between the electrodes will be large the EHD flow.

\section{Conclusion}

The $I-V$ characteristics on the spacing between the electrodes is fixed, the greater the applied voltage then increase ion current. The ion current of the EHD flow generator which use electrode configuration of pin-dual concentric rings is higher then the pin-ring electrode. Value of ion current during breakdown voltage, using electroda configuration pin-dual concentric ring, is lower than which use a pin-ring electrode. The EHD flow generator utilizing the electrode pin-dual concentric rings provide electric flux density which is greater than the pin-rings electrode. The smaller spacing between the electrodes, the greater the power that is used so that the ionization process large. The breakdown voltage is quickly achieved so that saturated flow rate is quickly achieved. This results the greater EHD flow velocity. 


\section{Acknowledgement}

The authors would like to thank the University of Diponegoro who has approved this research that could be funded by the Directorate of Research and Community Service Directorate General of Higher Education (DitlitabmasDikti) Ministry of Education and Culture (Ditlitabmas DGHE Kemendikbud) Operational Assistance State University (BOPTN) of Fiscal Year 2014, through the Budget Implementation List (DIPA) Diponegoro University Number DIPA 023.04.02.189185/2014 dated December 5, 2013

\section{References}

1. David B. Go, Raul A. Maturana, Timothy S. Fisher, Suresh V. Garimella,2008, Enhancement of external forced convection by ionic wind, International Journal of Heat and Mass Transfer 51, 6047-6053

2. Chakraborty,S.,I-Chien Liao, Adler, A., Leong,K.W., 2009, Electrohy drodynamics: A Facile technique to fabricate drug delivery systems, Advanced Drug Delivery reviews

3. Rada, M, Shooshtari, A., Ohadi,M.M.,2008, Experimental and numeral simulation of meso-pumping of liquid nitrogen -Application to cryogenic spot cooling of sensors and detectors, Sensors and Actuators

4. Jewell-Larsen,N.., H.Ran, Y.Zhung, M.Schswiebert and K.A.Honer Tessera, Electrohydrodynamic (EHD) Cooled Laptop, 25th IEEE SEMI-THERM Symposium

5. Huang , R.T., Sheu , W.J., Wang, C.C. ,2009, Heat transfer enhance ment by needle-Arrayed electrodes - An EHD integrated, cooling system, energy Conversion and Management

6. Kawamoto, H dan Umezu, S, 2008, Electrostatic microozone fan that utilizes ionic wind induced in pin-to-plate corona discharge system, Journal of Electrostatics, 66 pages

7. Timothy I.J. Goodenough, Peter W. Goodenough, Sylvia M. Goodenough, 2007, The efficiency of corona wind drying and its application to thefood industry, Journal Of Food Engineering, 80, 1233-123

8. Lai, F.C., 2010, A prototype of EHD-enhanced drying system, Journal of Electrostatics, 68,101-104

9. Rickard,M. dan Dunn-Rankin,D., 2007 ,Numerical simulation of a tubular ion driven-wind generator,

10. Journal of Electrostatics

11. Tsubonea,H, Uenoa,J, Komeilia, K, Minamic,S., Harveld,G.D., Hrashimaa, K., Chinge, C.Y., dan J.S. Changa J.S.,,2008, Flow characteristics of dc wire-nonparallel plate electrohydro dynamic gas pumps Journal of Electrostatics 66, 115-121

12. Nozomi Takeuchi, and Koichi Yasuoka, 2009, Gas Discharge Induced Electrohydrodynamic Flow in Narrow Channels, Manuscript received April 15, 2009.
13. June, M.S., Kribs, J., Lyons, K.M., 2011, Measuring Efficiency of positive and negative Ionic wind devices for comparison to fans and blowers, Journal of Electrostatics Volume 69 issues 4, pages 345-354

14. Zhang,J. 1, F.C. Lai, ,2011, Effect of emitting electrode number on the performance of EHD gas pump in a rectangular channel, Journal of Electrostatics 69, 486-493 